\title{
Interaction of components in 3d prf matrix and neuronal cells in vitro
}

\section{Commentary}

The task of modern neuro transplantology is to find adequate 3D matrix for transplanted cells. The requirements proposed for the $3 \mathrm{D}$ matrix in neurotransplantation consist in the following - the absence of toxicity, the possibility of biodegradation, the maintenance of integration and functional activity of targeted transplanted cells into the tissue. Recently, an attention is focused on the matrix obtained using plasma rich fibrin (PRF) to improve the results of stem cell transplantation. ${ }^{1}$ Studies have shown that the use of fat cells in combination with PRP (platelet-rich plasma) promotes the graft revascularization and improves the survival in transplantation. ${ }^{2,3}$ It is believed that the PRP properties are determined by platelets that are a source of growth factors containing in the $\alpha$-granules. Platelets circulate in blood stream in an inactive state until their contact with the damaged endothelium. Platelet activation is accompanied by degranulation with the release of growth factors - counting more than 20. PDGF (platelet-derived growth factor), TGF $\beta$ (transforming growth factor beta), IGF (insulin-like growth factor), VEFG (vascular endothelium growth factor) and EGF (epidermal growth factor) are the most important of them. ${ }^{4,5}$ Angiogenesis, cell proliferation, differentiation and formation of extracellular matrix are stimulated by growth factors. An important component of platelet $\alpha$-granules is also prothrombin that plays an important role in the platelet aggregation. PRF use allows to obtain the matrix, which $3 \mathrm{D}$ structure is provided by thrombin with included platelets, capable to active prolonged release of growth factors. ${ }^{1,-6}$ If necessary, the neuronal, mesenchymal or other stem cells can be enclosed in matrix.

This method has the following advantages: fibrin clot can be obtained for 1-2 hours before the need to use; this is autologous material that removes the ethical issues, problems of immune conflicts and infection; this is an inexpensive method. There are few studies where this method is used, but the positive results are emphasized by some authors today. ${ }^{2,3,6,7}$

In our work 3D PRF matrix was obtained from human venous blood samples ${ }^{8}$ by centrifugation at $3000 \mathrm{rpm}$ for $10 \mathrm{~min}$ using the coagulation activator $\mathrm{SiO}_{2}$ (Vacumed, F.L. Medica Italy) in $10 \mathrm{ml}$ vacutainer. After centrifugation, it settles in three layers, the upper straw-colored acellular plasma, middle portion containing the fibrin clot, and red-colored lower portion containing red blood cells. The upper straw-colored layer is removed and middle portion is collected, $2 \mathrm{~mm}$ below to the lower dividing line, which is the PRF. To study the effect of fibrin matrix density on the vital functions of nerve cells and the culture results, 3D PRF of different density (high and low) were used. Their platelet count was 200 and 100 thousand per $\mathrm{ml}$ respectively. The suspension of the brain nerve cells of newborn rat was administered into the middle of the clot by injection and was applied to its outer surface under different experimental samples. Culture was carried out in medium DMEM (Dulbecco's modified Eagle's medium) (PAA, Austria), enriched with 10\% serum of FBS (fetal bovine serum) (PAA, Austria) for 10 days at $37^{\circ} \mathrm{C}$ and $5 \% \mathrm{CO}_{2}$.

Monitoring of nerve cell culture showed the active formation of
Volume 2 Issue 5 - 2017

\begin{abstract}
Tsymbalyuk VI,Vasylyeva IH, Oleksenko NP SI Institute of Neurosurgery n. acad.A. Romodanov NAMS of Ukraine, Ukraine
\end{abstract}

\begin{abstract}
Correspondence: : Oleksenko NP, SI “Institute of Neurosurgery n. acad.A. Romodanov NAMS of Ukraine, Ukraine,Email n.oleksenko@gmail.com
\end{abstract}

Received: May 17, 2017 | Published: August 04, 2017

growth zone, axonal invasion, the establishment of contacts between cells, the formation of confluence in cell layer when cells were applied on the outer surface of 3D PRF matrix (Figure 1A-1C). When cells were administered inside 3D PRF matrix the active cell migration on the outer surface of the matrix, the formation of contacts by cells in the middle of the matrix, and the network of processes forming neurite-glial fibers with their invasion outside were noted. The dense layer is form by the cells (Figure 1D-1F). Partial lysis of fibrin matrix was revealed at the end culturing (Figure 1B).

A clear difference in the rate of axonal invasion through matrix towards the surrounding cells was noted by us. When using 3D matrix with high density this process occurred more slowly (Figure $1 \mathrm{G})($ Figure $1 \mathrm{H})$. Thus, our studies have shown that the formation of supportive environment without toxic effect on nerve cells that actively form the network of branches, establishment of contacts and formation of cell layer with high confluence is a result of 3D PRF matrix use. We consider it advisable to continue studying the properties of 3D PRF matrix as a substrate for nerve cell transplantation.

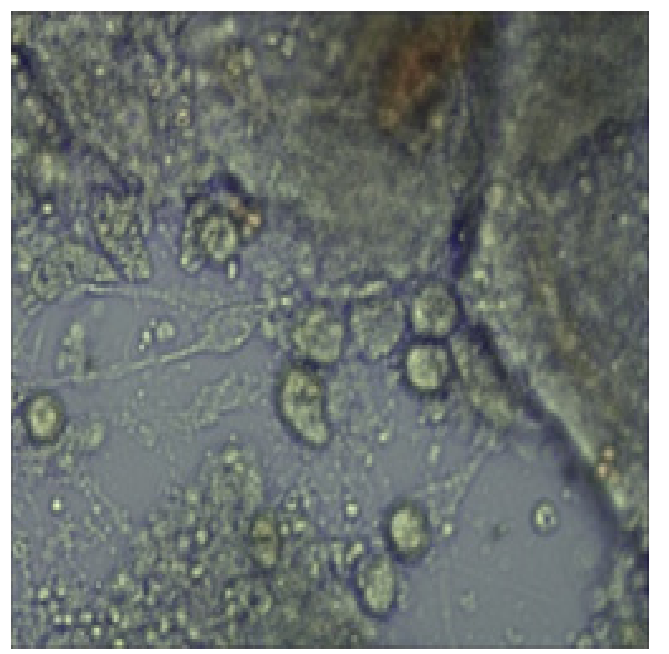

A. 3D PRF matrix of low-density, external application of cells, contact establishment, 3 days in culture, $x 400$. 


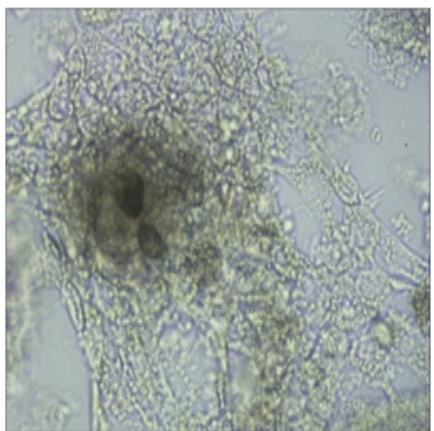

B. PRF 3D matrix of low density, external application of cells, 5 days in culture, establishment of contacts, formation of processes network, $\times 200$.

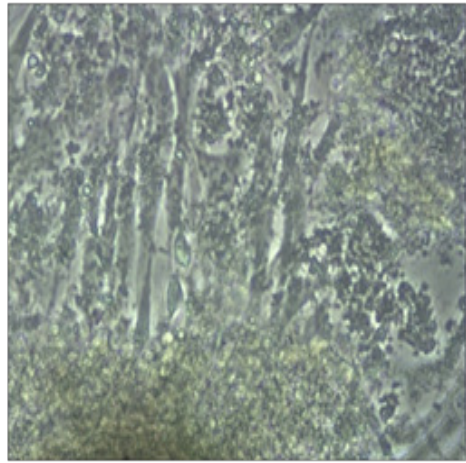

C. 3D PRF matrix low-density, external application of cells, 8 days in culture, formation of confluent cell layer, $x 400$.

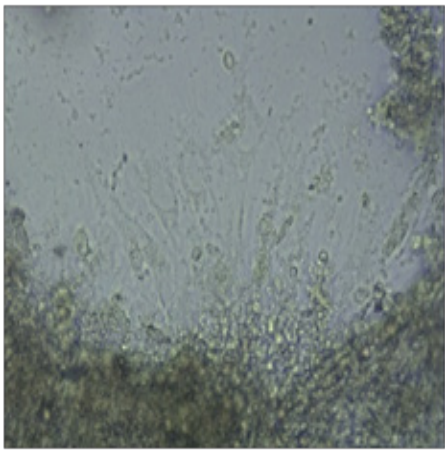

D. 3D PRF matrix of low-density, internal application of cells, external surface,

3 day in culture, cell eviction, formation of growth zone, $x 100$.

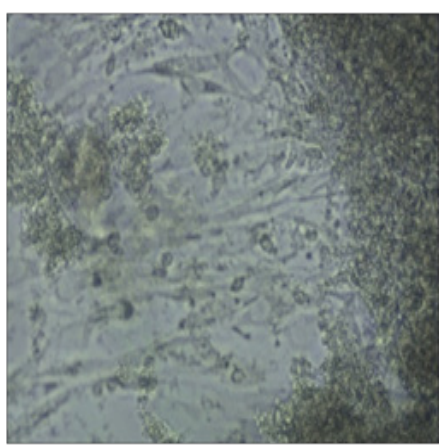

E. 3D PRF matrix of low-density, internal application of cells, external surface, 3 day in culture, cell eviction, formation of growth zone and confluent cell layer outside the matrix, formation of growth zone, x 200.

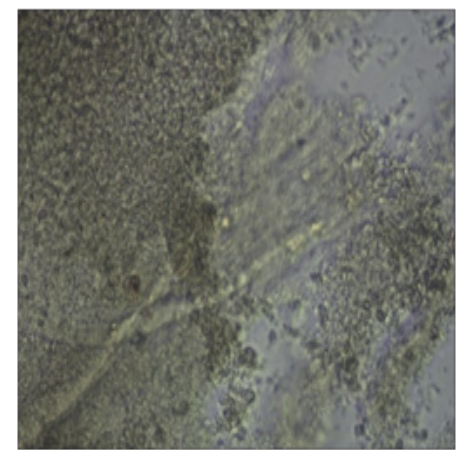

F. 3D PRF matrix of low-density, internal application of cells, external surface, 5 day in culture, formation of confluent cell layer and neurite-glial fibers invasion inside of the matrix, $\mathrm{x} 100$.

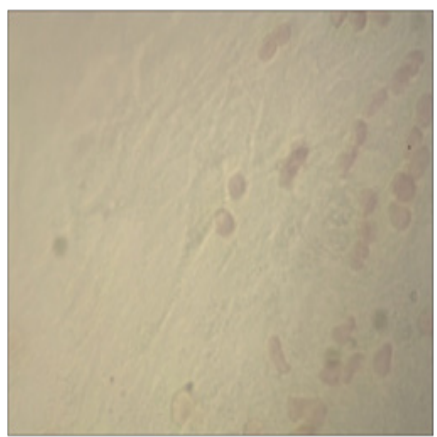

G. 3D PRF matrix of high-density, internal application of cells, view of cells inside, 8 days in culture, $\mathrm{x} 200$.

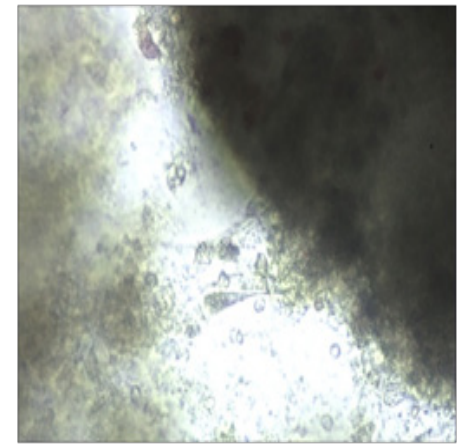

H. 3D PRF matrix of high-density, internal application of cells, external surface, 8 days in culture, $\mathrm{x} 200$.

Figure I 3D PRF matrix of high- and low-density with application of nerve cells suspension in culture condition.

\section{Acknowledgements}

None.

\section{Conflict of interest}

The author declares no conflict of interest.

\section{References}

1. Dohan Ehrenfest DM, Del Corso M, Diss A, et al. Three dimensional architecture and cell composition of a Choukroun's platelet-rich fibrin clot. J Periodontol. 2010;81(4):546-555. 
2. Modarressi A. Platlet Rich Plasma (PRP) Improves fat grafting outcomes. World J Plast Surg. 2013;2(1):6-13.

3. Cervelli V, Gentile P, Grimaldi M. Regenerative surgery: use of fat grafting combined with platelet-rich plasma for chronic lower-extremity ulcers. Aesthetic Plast Surg. 2009;33(3):340-345.

4. Amable PR, Carias RB, Teixeira MV, et al. Platelet-rich plasma preparation for regenerative medicine: optimization and quantification of cytokines and growth factors. Stem Cell Res Ther. 2013;4(3):67.

5. Weibrich G, Kleis WK, Hafner G, et al. Growth factor levels in platelet-rich plasma and correlation with donor age, sex, platelet count. $\mathrm{J} \mathrm{Cra-}$ niomaxillo fac Surg. 2002;30(2):97-102.
6. Been A, O'Brein T, Pandit A. Fibrin as a delivery system for therapeutic drugs and biomoleculars. Tissue Eng Part B Rev. 2009;15(2):201-214.

7. Voss A, McCarthy MB, Allen D, et al. Fibrin scaffold as a carrier for mesenchymal stem cells and growth factors in a sholder rotator cuff repair. Arthrosc Tech. 2016;5(3):e447-451.

8. Tatullo M, Marrelli M, Cassetta M, et al. Platelet rich fibrin (P.R.F.) in reconstructive surgery of atrophied maxillary bones: Clinical and histological evaluations. Int J Med Sci. 2012;9(10):872-880. 